\title{
The Turin Papyrus Online Platform (TPOP): An Introduction
}

\author{
Susanne Töpfer
}

In recent years, scholarly communities as well as the general public have been increasingly requesting open access to museum collections, prompting institutions to offer online catalogues, mostly of selected objects, in some cases even of their complete collections. Major Egyptian papyrus collections, however, have so far been extremely slow in adopting this open-access approach. Until recently, this was also true of the Museo Egizio in Turin, which houses one of the largest collections of Egyptian antiquities worldwide. The TPOP project aims to conserve, document, digitize and contextualize hundreds of papyrus manuscripts and thousands of fragments in a newly created online platform. This platform will enable scholars to work collaboratively on the material and will provide a straightforward publication outlet for both the scholarly and the general public. It aims to generate value beyond the mere preservation of material culture. The virtual "restoration" of papyri by digitally reconstructing them and joining fragments online makes possible what physical restoration does not allow, namely, the long-term preservation of written cultural heritage and its accessibility by anyone from anywhere and at any time.

$$
\begin{aligned}
& \text { ملخص البحث: } \\
& \text { طلبت المجتمعات الأكاديمية وعامة الناس في السنوات الأخيرة الوصول بحرية إلى المجموعات الخاصة بالمتاحف، مما }
\end{aligned}
$$

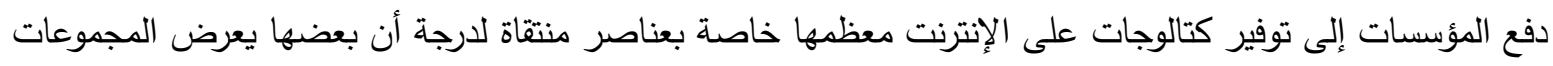

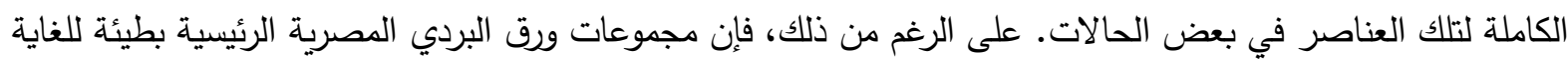

$$
\begin{aligned}
& \text { حتى الآن في تبني نهج الوصول الحر إليها. وهذا ينطبق أيضًا على المتحف المصري في تورينو حتى وقت قريب، والذي لحني }
\end{aligned}
$$

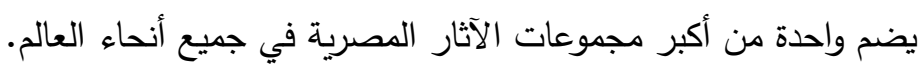

$$
\begin{aligned}
& \text { يهدف مشروع قاعدة بيانات البردي عبر الإنترنت في تورينو ”TPOP“" إلى حفظ المئات من مخطوطات البردي وآلاف } \\
& \text { الأجزاء الممزقة وتوثيقها ورقمنتها وفهم سياقها في منصة إلكترونية تم إنثاؤها حديثًا. ستعمل هذه المنصة على على تمكين }
\end{aligned}
$$

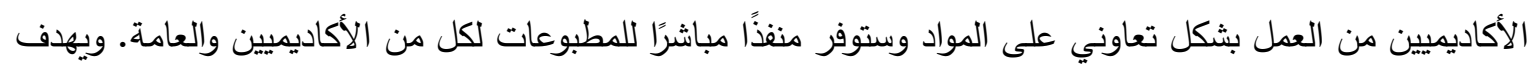

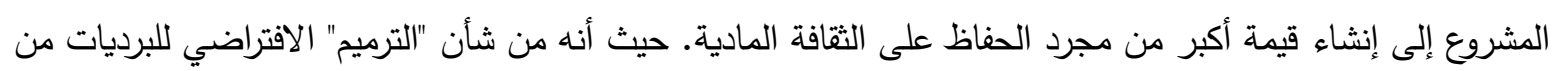

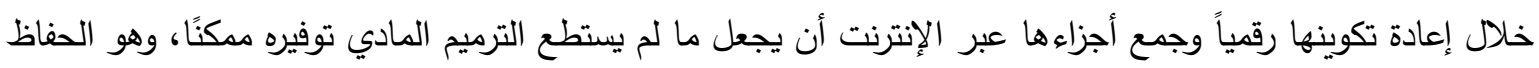

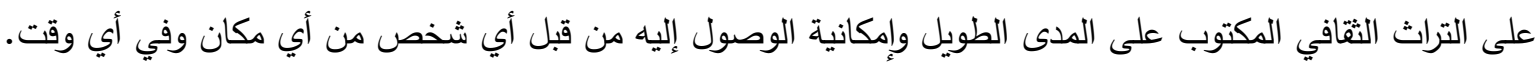

\section{Introduction}

The Museo Egizio holds one of the world's most significant papyrus collections. It comprises nearly 500 whole or reassembled manuscripts and over 17,000 papyrus fragments. About half of these texts are written in Egyptian (in the hieroglyphic or hieratic script), while the rest are written in Demotic, Greek, Coptic, or Arabic. Most of the papyri were acquired by the government of Piedmont in 1824 from Ber- nardino Drovetti (1776-1852), the French consul in Egypt at the time. Most of Drovetti's antiquities were procured in western Thebes. The rest of the papyrus collection comes from the early twentieth century excavations of the Turin museum in Gebelein, Asyut and, again, western Thebes.

The collection houses a number of important and unique texts ${ }^{1}$ that are well known to the Egyptological community and the public at large from publi- 
cations and from their being displayed in the museum galleries. These include: a group of Old Kingdom administrative accounts from Gebelein (Suppl. 17507/002-006); ${ }^{2}$ the "Turin King List" also known as "Royal Canon", a fragmentary papyrus containing a list of Egyptian kings until the Seventeenth Dynasty (Cat. 1874); ${ }^{3}$ the "Turin Judicial Papyrus", a record of a conspiracy against King Ramesses III (Cat. 1875); ${ }^{4}$ the "Satirical-Erotic Papyrus", giving a glimpse of the humour of the inhabitants of the settlement (Cat. 2031 = CGT 55001); the "Turin Goldmine Papyrus", the oldest known geological map (Cat. 1879+1969+1899 rt.); ${ }^{6}$ and the "Turin Strike Papyrus", documenting the earliest recorded strikes in world history, under Ramesses III (Cat. 1880). ${ }^{7}$ Even census records have been found among the thousands of papyrus fragments in the Museo Egizio, which is quite exceptional in Egypt before the Graeco-Roman period, most notably a manuscript known as "Stato Civile", consisting of lists of households and their members (Cat. 1963). ${ }^{8}$

Among the approximately 170 funerary manuscripts held in the Museo Egizio, two in particular stand out, namely, the Eighteenth Dynasty Book of the Dead of Kha, written in cursive hieroglyphs by a scribe with a neat handwriting, accompanied by high-quality colour vignettes (Suppl. 8438), ${ }^{9}$ and the Book of the Dead of Iufankh, the basis for Richard Lepsius's seminal study of 1842, in which he introduced the spell numbering system still in use today (Cat. 1791). ${ }^{10}$

Besides hieratic and hieroglyphic manuscripts, the Museo Egizio houses several Demotic and Greek documentary manuscripts, including title deeds, contracts and receipts. Particularly notable among these are the bilingual family archive of Totoes (Provv. 5056-5057, 5064-5065, 6134; Suppl. 6068-6120, 6123-6125), which was found in two sealed jars north of the Hathor temple precinct in Deir el-Medina, ${ }^{11}$ and the archive of the "embalmer priest" (parachystes) Amenothes (Cat. 2129, 2131 2133-2136, 2138-2139, 2141-2143, 2146, 2154$2155,2158,2160) .^{12}$

Furthermore, the Museo Egizio holds one of the most important collections of Coptic literary papyri. ${ }^{13}$ Among the Coptic papyrus material acquired in 1824 from Drovetti were about seventeen fragmentary codices. They date to the late seventh or early eighth century $\mathrm{AD}$ and originate from the cathedral of Thi(ni)s, modern Ǧirğa. ${ }^{14}$

The vast majority of the papyrus manuscripts in the Museo Egizio are unpublished and unknown to a wider audience. Most date from the Ramesside period (c. 1300-1050 BCE) and are highly likely to originate from the settlement of Deir el-Medina, which housed the families of the workmen who built the royal tombs. ${ }^{15}$ They probably belonged to members of the administration of the royal necropolis.

\section{Ramesside Papyri in the Museo Egizio}

The Ramesside manuscripts in the Turin collection range in content from documentary (e.g. necropolis and temple administration, juridical texts) to literary, ritual, magical and religious. Almost all of them are written in hieratic, and in either the Classical or the Late Egyptian language. The importance and nature of the Turin Ramesside papyrus archive have been highlighted by scholars such as W. Pleyte, F. Rossi, G. Botti, A. Gardiner, J. Černý, J.J. Janssen, A. Roccati, R.J. Demarée, S. Demichelis and others. The archive comprises several thousands of papyrus fragments. Some 300 of these have been reassembled into larger manuscripts (Fig. 1), ${ }^{16}$ mostly by the above-cited Egyptologists, who thus laid the foundation for the further study of the Turin hieratic manuscripts.

An overview of already inventoried papyri in Turin is provided in the Deir el-Medina Database of Leiden University (https://dmd.wepwawet.nl/, including a systematic bibliography of Deir el-Medina studies). This is currently the most extensive reference tool for the textual legacy of the administration of the royal necropolis in Ramesside Egypt. 145 Turin papyri with catalogue numbers are currently recorded in this database. Many of these are listed as unpublished and the information provided about them is mainly based on J. Černý's notebooks (http://archive. griffith.ox.ac.uk/index.php/cerny-collection), which were copied in K. Kitchen's multivolume collection of Ramesside inscriptions. ${ }^{17}$ For others, the information is based on the facsimiles in $\mathrm{W}$. Pleyte and F. Rossi's catalogue, ${ }^{18}$ on old black-and-white photographs, or on brief examinations of the originals by Leiden scholars. Linked with the Leiden DeM Database is the papyrological online tool Trismegistos (http://www.trismegistos.org/), which records 


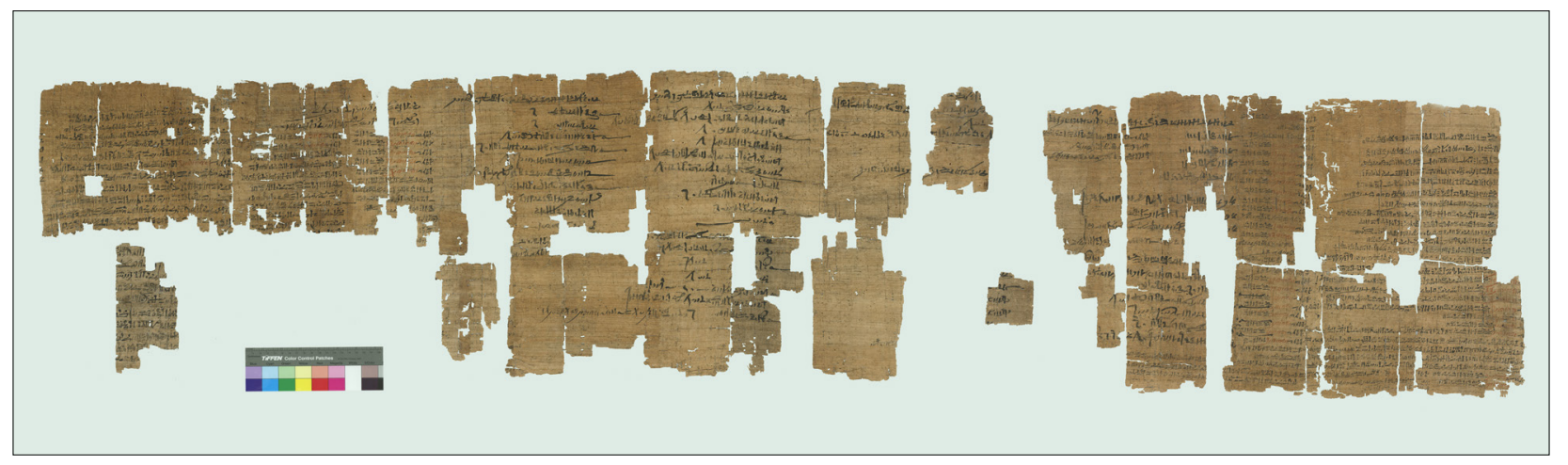

Fig. 1: Journal of year 17 of Ramesses IX (P. Turin Cat. 2083/177-179 + 2983/181 + 2083/183 + 2082/172 + 2082/175 + 2082/177 + 2083/179 + 2073/145 + 2076/154-155 verso). Scan enhancement by Martina Landrino/Museo Egizio.

a total of 474 Turin papyri with inventory numbers (Egyptian, Demotic, Greek and Coptic).

Some of the assembled documents are more or less complete manuscripts, though with partly unidentified texts. There are, however, still thousands of tiny fragments, ${ }^{19}$ which belong either to these ensembles or to yet other, unidentified texts (Fig. 2). Despite having been part of the museum collection for almost two centuries, and despite their historical importance, the more than 10,000 papyrus fragments are neither stored according to state-ofthe-art guidelines for the conservation of papyri nor documented in the existing museum database. As a consequence, this important material has remained unknown and unpublished, except for a very limited number of documents.

The documentation and reconstruction of the Turin fragmentary manuscripts is a fairly difficult task, mainly due to the fact that it is not possible to spread the individual pieces on a table and try to connect them manually - as we do when assembling a jigsaw puzzle - due to the fragile condition of the papyri and the often non-existent space in the storerooms. Furthermore, when we assemble a puzzle we start from a set of pieces that certainly belong to it; in the case of a papyrus document in an archive such as ours, instead, pieces (possibly) belonging to the same manuscript have to be singled out from thousands of fragments belonging to hundreds of different documents. The identification of fragments of the same papyrus roll is based on material features (such as the pattern of the fibres of the papyrus and its colour), on the text content and layout (including features such as the distance between lines or the density of the ink) and often on palaeography (handwriting) and on various sorts of scribal practices. The distinction between material and writing is of fundamental importance. Assessment of the physical medium is crucial; indeed, the evaluation of each papyrus as a material object can often be as important for its interpretation and contextualisation as the text written upon it. An Egyptologist's memory is unable to retain all these features of the material and writing for thousands of papyrus fragments; he or she must therefore rely on a relational software tool that suggests possible joins between fragments of papyrus documents on the basis of collected and structured metadata.

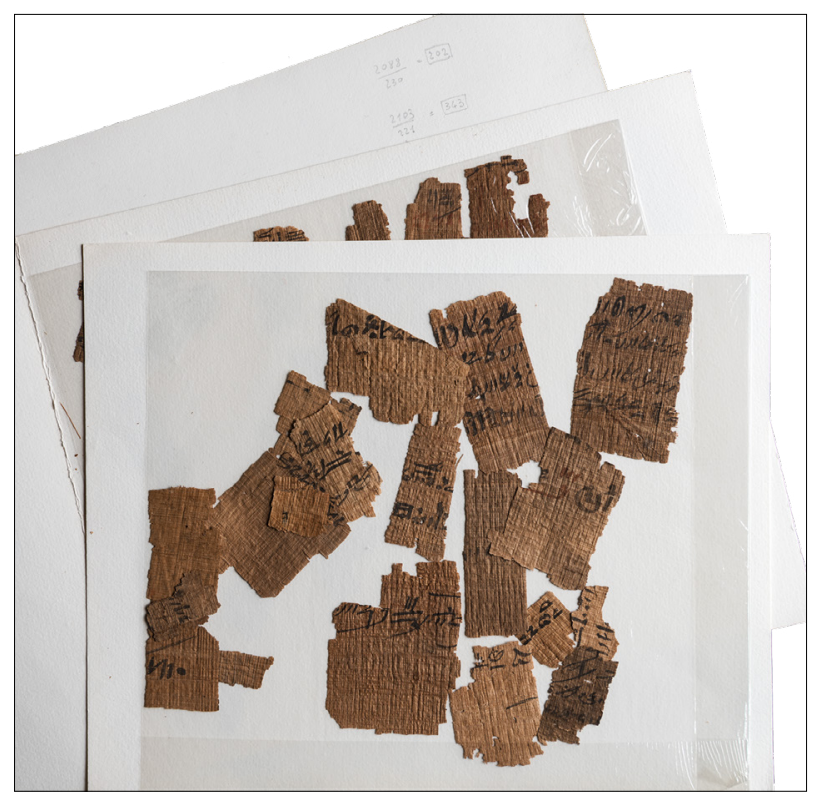

Fig. 2: Undocumented hieratic fragments from Deir el-Medina. Photo by Nicola Dell'Aquila/Museo Egizio. 


\section{Turin Papyrus Online Platform (TPOP)}

Since 2015, the Museo Egizio, together with some of the specialists on Ramesside hieratic manuscripts - namely: Günter Burkard (Munich), Rob J. Demarée (Leiden), Andreas Dorn (Uppsala), Kathrin Gabler (Basel), Maren Goecke-Bauer (Munich), Fredrik Hagen (Copenhagen), Ben J.J. Haring (Leiden), Stéphane Polis (Liège), Lutz Popko (Leipzig) and Daniel Soliman (London) - have been working on a collaborative project with the following objectives:

- Conservation and consolidation of the thousands of papyrus fragments, preserving their ancient appearance and using reversible methods.

- Recording the fragments as well as the already inventoried papyri by entering metadata about their physical features and the writing and drawings they bear in a newly created online database, which will be available to both the general public and scholars worldwide.

- Processing high-resolution digital images of the material and systematically linking them with open metadata in order to enable scholars to work collaboratively on the material and provide a straightforward publication outlet for scholars and the general public.

- Reconstructing individual manuscripts in the Turin collection by digitally joining fragments with the help of the online database and using digital rearrangement as a template for their physical reconstruction.

- Communication of the Egyptological research results to the general public and integrating them in temporary and permanent exhibitions by means of virtual reconstructions.

The central concept of this project is the "Turin Papyrus Online Platform” (TPOP), an open-access repository. It shall facilitate all stages in the workflow, from the conservation of the papyrus material and the recording of data to their online publication. It is a multi-user platform, enabling the community of experts based at different European locations to contribute data. Furthermore, at the front end it will automatically adapt to the needs of different users, from the interested layman to the highly specialized philologist and papyrologist. After conservation of the material and data entry, the three main tasks of the workflow - (1) data documentation, (2) data connection, (3) data contextualisation - correspond, respectively, to three levels in the Thot Data Model (TDM). ${ }^{20}$ The three key elements of the TDM are: the Object, in our case to a papyrus fragment; the Document, in our case a papyrus roll reconstituted from several Objects (= fragments); and the Witness, a term designating one or more texts written on a Document (= papyrus roll). Any papyrus roll (= Document) potentially contains several texts (= Witnesses). On a single roll of papyrus, one may find a copy of a letter to the authorities, a note about a judicial case, a hymn to Pharaoh and a drawing to be copied on a coffin. Each of these elements is treated as a different Witness, having its own distinctive features (text type, handwriting, content, etc.). It shall then become possible to integrate the transliteration, transcription and translation of each witness into a richly annotated corpus of Egyptian texts in order to allow full access to the material.

Four stakeholders will benefit from the results and impact of the Turin Papyrus Online Platform:

1. Egyptologists and historians, who will have online access to this digital repository of written material culture and will be offered access to an online platform where scholars can collaborate in the edition of the papyri.

2. Digital Humanities, as a result of the implementation of a new technological tool (TPOP) for the documentation and reintegration of the past, a tool which will not be a mere update of "Digital Papyrology", ${ }^{21}$ but will go beyond textual analysis by creating a collaborative digital framework applicable to all kinds of material culture.

3. The Museo Egizio, whose tangible and virtual cultural heritage will be saved into a digital repository enabling the staff to manage and preserve the material in the long term, on the one hand and, on the other, to display scattered material, digitally reunited in a "virtual" museum.

4. The general public, since information will be provided about the complete workflow and its outcomes in the physical and virtual museum in order to make both the papyri themselves and the research done on them understandable and accessible to the non-Egyptologist public in any place and at any time. 


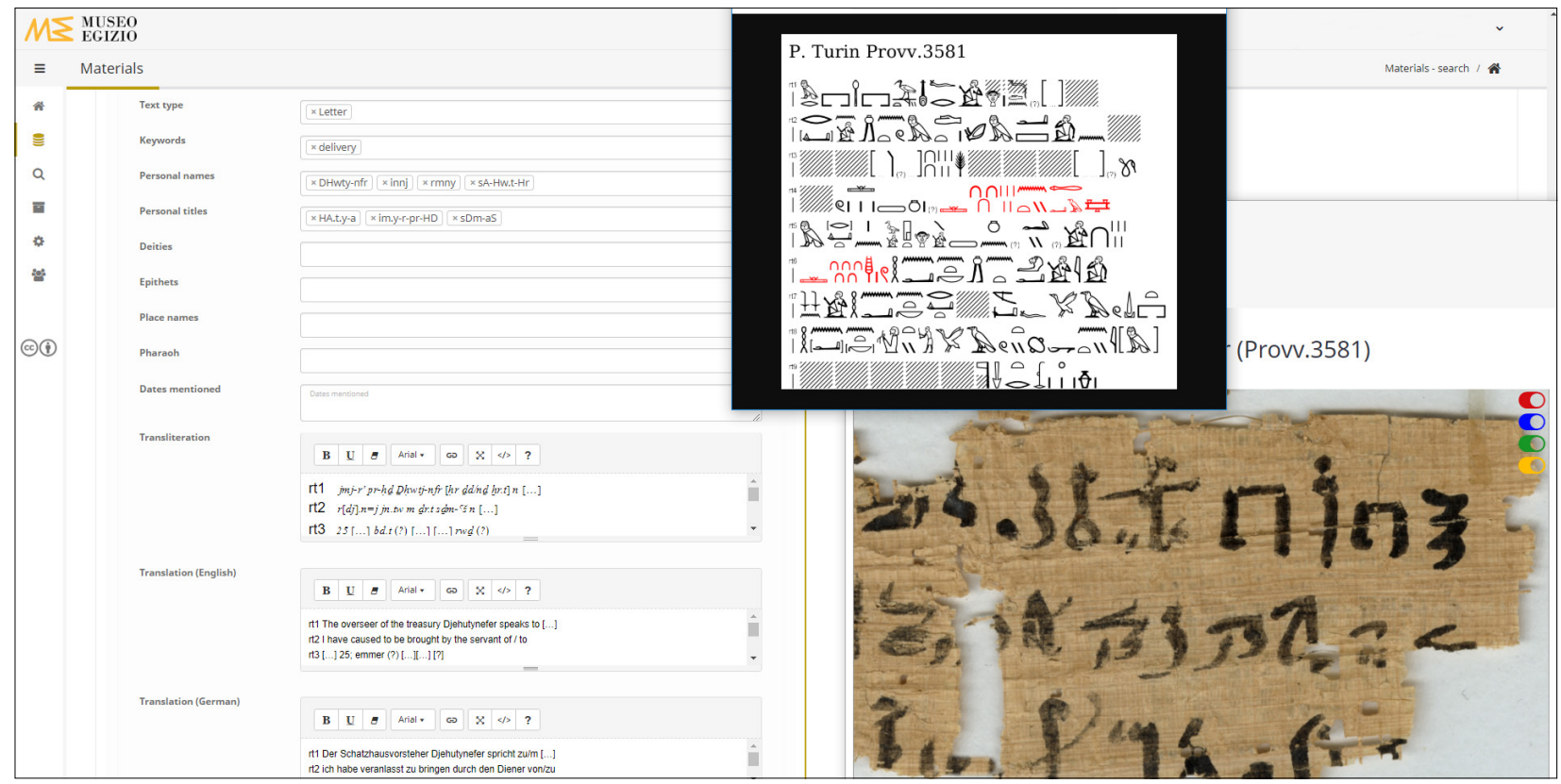

Fig. 3: Excerpt from the database, section "text content"; example: P. Turin Provv. 3581 (editors: K. Gabler and D. Soliman).

\subsection{State of the art and future direction}

The Museo Egizio has been developing the TPOP since 2017 (supervision: Susanne Töpfer) in collaboration with the IT company $3 \times 1010$ (http:// www.3 $\times 1010 . i t /)$ and with the contribution of the above-mentioned group of specialists. Since the end of 2017 , the platform is fully functional. It allows the museum staff to upload images of all the papyri and append a wealth of information to them. Each object is documented with metadata about its inventory number(s), current location, physical features (including sheet joins and overlaps, measurements and material) and the conservation/restoration process, as well as the features of the text witnesses it carries (state of preservation, writing, layout, scribal practice, mode of inscription, type of text, content, keywords, date, etc. Fig. 3) and drawings (type, colour, grid, etc.), if any. The vocabulary for the dropdown lists for the description of the witnesses and their dating was imported from the ongoing Thot project (THesauri \& OnTology for Documenting Ancient Egyptian Resources; http://thot.philo.ulg. ac.be) and the Leiden Deir el-Medina Database. The open-source JSesh hieroglyph-writing software ${ }^{22}$ is integrated into the platform: the hieroglyphic text can be produced automatically from the Manuel de Codage field. The images are produced as high-resolution TIFF scans at a 1:1 scale.

Similarly to Google Maps navigation, the images are uploaded in a creation engine and transformed into tiles visualized in a web viewer. This viewer will allow scholars to attach comments to any position on the surface of the papyrus by using popup forms. The list of comments will be shown at the bottom of the page and the exact position in the image will be highlighted by clicking on a comment (Fig. 4).

Uploads of additional PDF documents are possible (subject to copyright laws), such as the relevant entries in the catalogue by Fabretti et al. ${ }^{23}$ or the facsimiles by Pleyte and Rossi ${ }^{24}$ (Fig. 5). Furthermore, Rob Demarée has entrusted the Museo Egizio with hundreds of copies of his transcriptions and notes, which are a major resource for the joining of fragments and rearranging of documents. The digitisation and processing of these notebooks for the database has been completed and the PDFs have been uploaded, although they are currently only visible to the collaborating partners.

Since March 2018, a beta version of the platform is available to a selected group of users ${ }^{25}$ who have editor rights for the witness level in order to contribute information about the texts. To date, about 283 entries (= objects) have been created and more than 409 images and 148 PDF-documents have been uploaded. These include the 145 Turin papyri with catalogue numbers recorded in the Leiden Deir el-Medina Database, as well as another 138 hieratic papyri (ranging in content from documentary to 


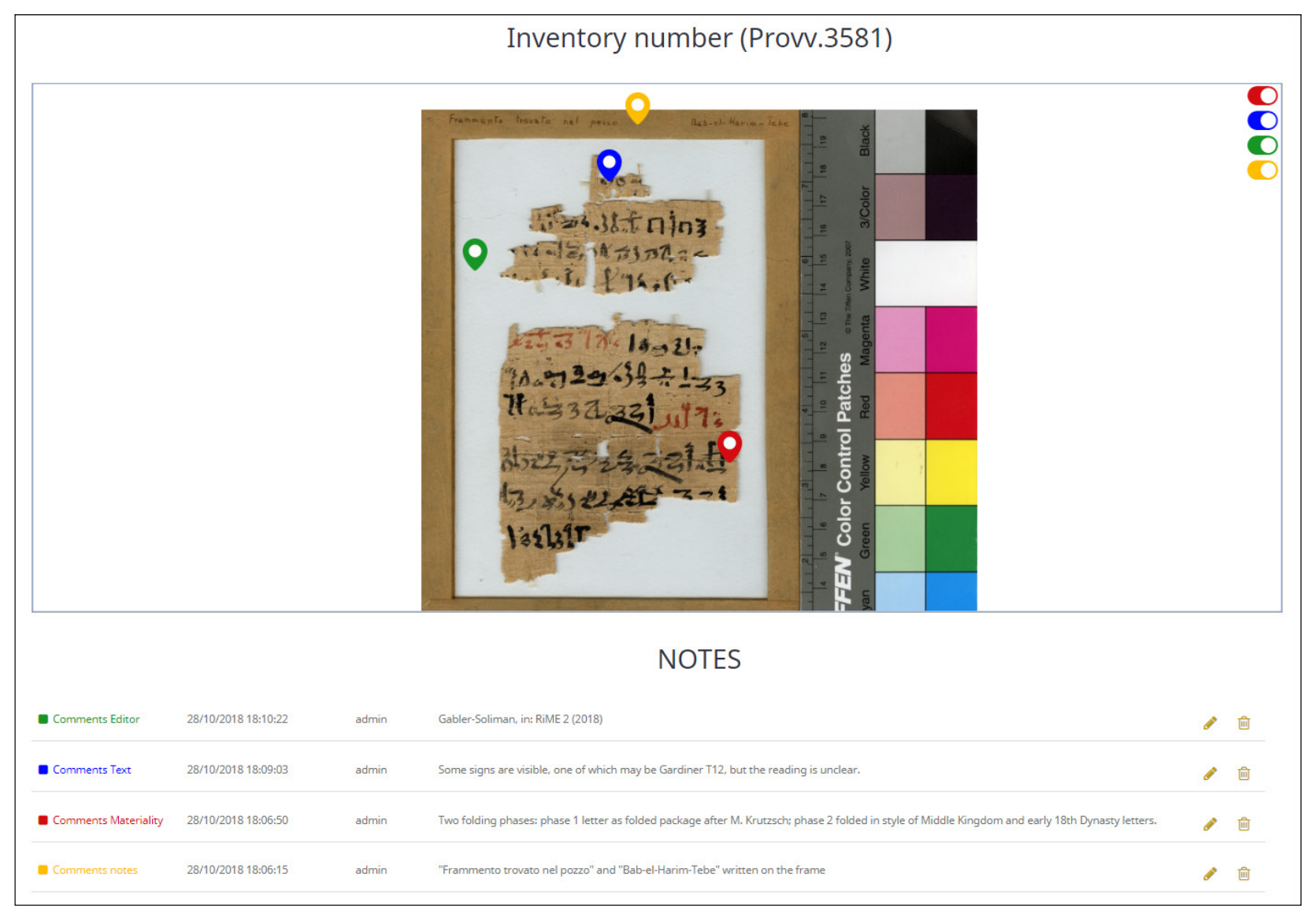

Fig. 4: Excerpt from the image navigator; example: P Turin Provv. 3581 (editors: K. Gabler and D. Soliman).

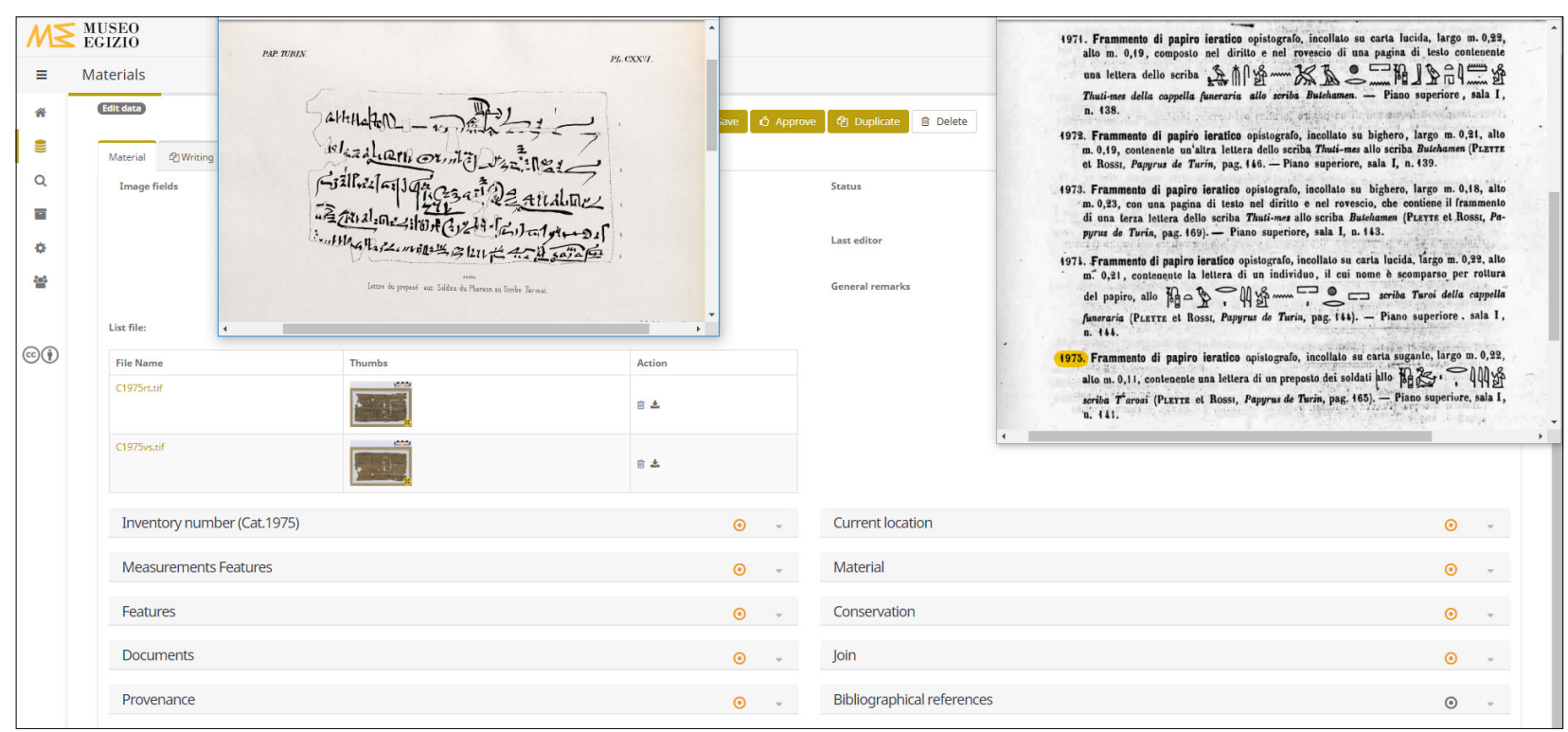

Fig. 5: Excerpt from the database, section "material", upload of PDF documents; example: P. Turin Cat. 1975.

literary, ritual and magic) with inventory numbers. By the spring of 2019, the online platform will be fully accessible via a newly created website for registered users. The wealth of information contained in the Turin manuscripts potentially holds great appeal for the layperson; therefore the front end of the platform will provide an interface allowing the general public to retrieve and display information stored within the database. Furthermore, the website will provide a backstage view where users can learn about the online platform, the workflow of papyrus documentation, ongoing restoration and the research conducted by scholars on Turin papyri, as well as about collaborative research projects. 
Over the next few years, the platform will be constantly extended and enhanced, focusing on linked open data. While the staff of the Museo Egizio will continue with the conservation, consolidation and documentation of the thousands of fragments within this platform, additional support for the group of collaborative partners will be necessary for supplying metadata for the witness-level and contextualise the text content and scribal practices. For that purpose, the Museo Egizio is funding two doctoral students and a post-doctoral one whose research projects focus on Ramesside hieratic papyri in the Museo Egizio. ${ }^{26}$

Furthermore, from March 2019 onward the museum will become a partner in an SNF-FNRS Lead Agency (http://www.snf.ch/en/funding/projects/ lead-agency/Pages/default.aspx) joint project of the universities of Basel and Liège entitled "Crossing Boundaries: Understanding complex scribal practices in Deir el-Medina". ${ }^{27}$ This project aims to study the heterogeneous Ramesside papyri from Deir el-Medina held in the Turin collection with a particular focus on the specific scribal practices of the individual agents producing the texts. The results of the project (information about material aspects, edition and reconstruction of texts, etc.) will be incorporated in the Turin Papyrus Online Platform. The "Crossing Boundaries” project will provide financial support to employ a certified restorer who will take care of the conservation and consolidation of these numerous fragments; many papyri need to be cleaned, unfolded, straightened, and anchored with correctly aligned fibres in order to improve (or simply allow) legibility, and to allow them to be reproduced photographically so they can be worked on remotely. Moreover, this project envisages the development of a digital light-table that will allow papyrologists and Egyptologists to make virtual joins of papyrus fragments by manipulating their digital images.

\subsection{Beyond Ramesside papyri}

In the long run, open-access documentation and digitisation in the Turin Papyrus Online Platform will be extended to include all the papyrus material held in the Museo Egizio, including the funerary papyri from the Third Intermediate Period to the Roman period, and the Demotic, Greek, Coptic and
Arabic documentary and literary manuscripts (cf. Figs. 6, 7, 8); of which the museums holds thousands of fragments, most likely from the Turin museum's early twentieth century excavations in Hermopolis, Asyut, Western Thebes and, above all, Gebelein. These papyrus fragments are in a very fragile condition. They need to be first carefully consolidated and subsequently digitised in order to provide the basis for further research on the non-Ramesside material. This material will also be made available online, nearly one hundred years after it entered the museum.

\subsection{Final remarks}

This Museo Egizio aims to employ digital information technologies to restore fragmentary written cultural heritage and make it virtually accessible across borders and disciplinary boundaries. The Turin Papyrus Online Platform seeks to generate value going beyond the preservation of material culture. The virtual "restoration" of papyri by means of digital documentation, connection and networking makes possible what physical restoration does not allow, namely, the preservation of written cultural heritage in the long run and its accessibility by anyone from anywhere and at any time. The Museo Egizio is among the first museums to distance itself from the practice of granting permission to publish individual manuscripts to one single scholar, a policy which typically results in only few publications in proportion to the amount of papyri.

\section{Excursus: Cat. inventory numbers}

The Museo Egizio in Turin has several types of mutually exclusive inventory numbers. ${ }^{28}$ Special difficulties arise for the papyri bearing Cat.-inventory numbers. Cat. (sometimes also abbreviated as C.) stands for "Catalogo", i.e., the numbers assigned to the museum's objects in the catalogue by Fabretti et al. (2 vols., 1882 and 1888), notably including the Drovetti collection. In the first volume of the catalogue by Fabretti et al. (1882), 391 inventory numbers are assigned to hieratic or hieroglyphic papyri (Cat. 1769-2160). Some of these (Cat. 2042-2114) comprise several fragments belonging to different manuscripts, which were given sub-numbers (nos. 1-504) by Fabretti et al. Old labels with the 


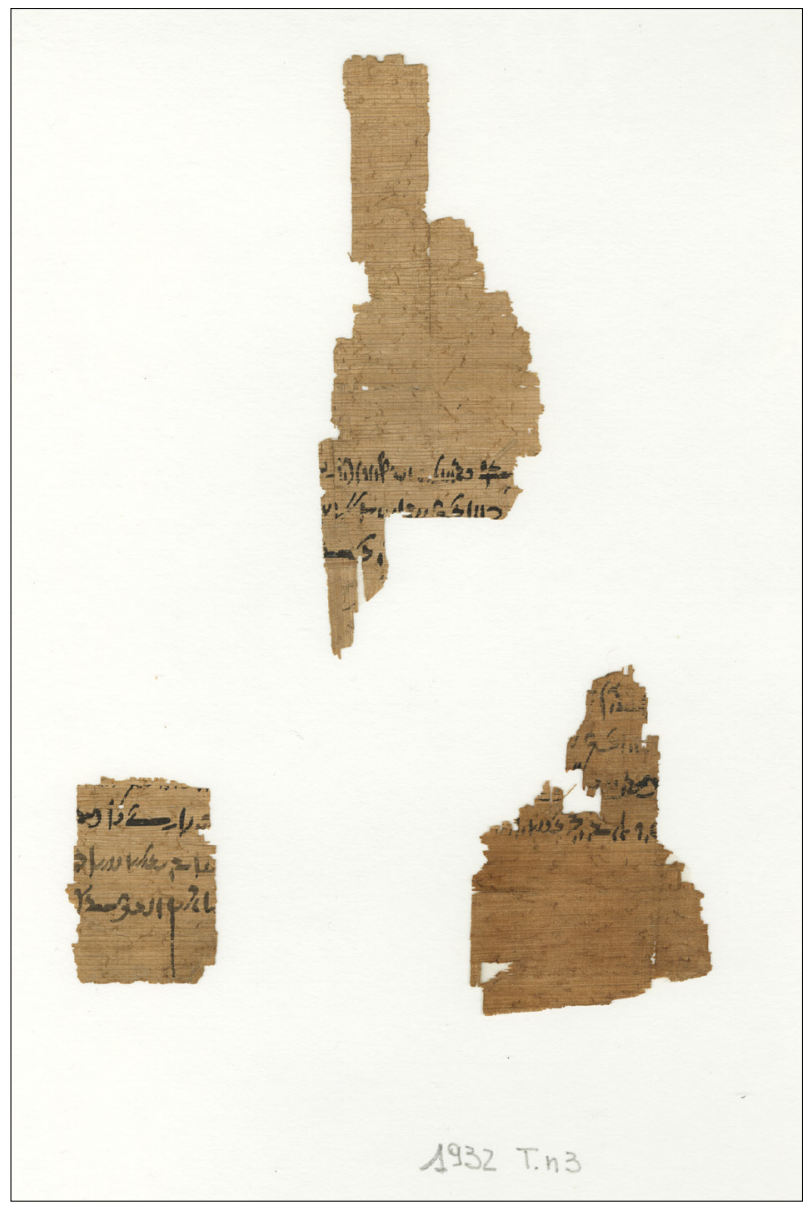

Fig. 6: Undocumented Demotic fragments from Gebelein, CP 170, layer 1. Scan by Museo Egizio.

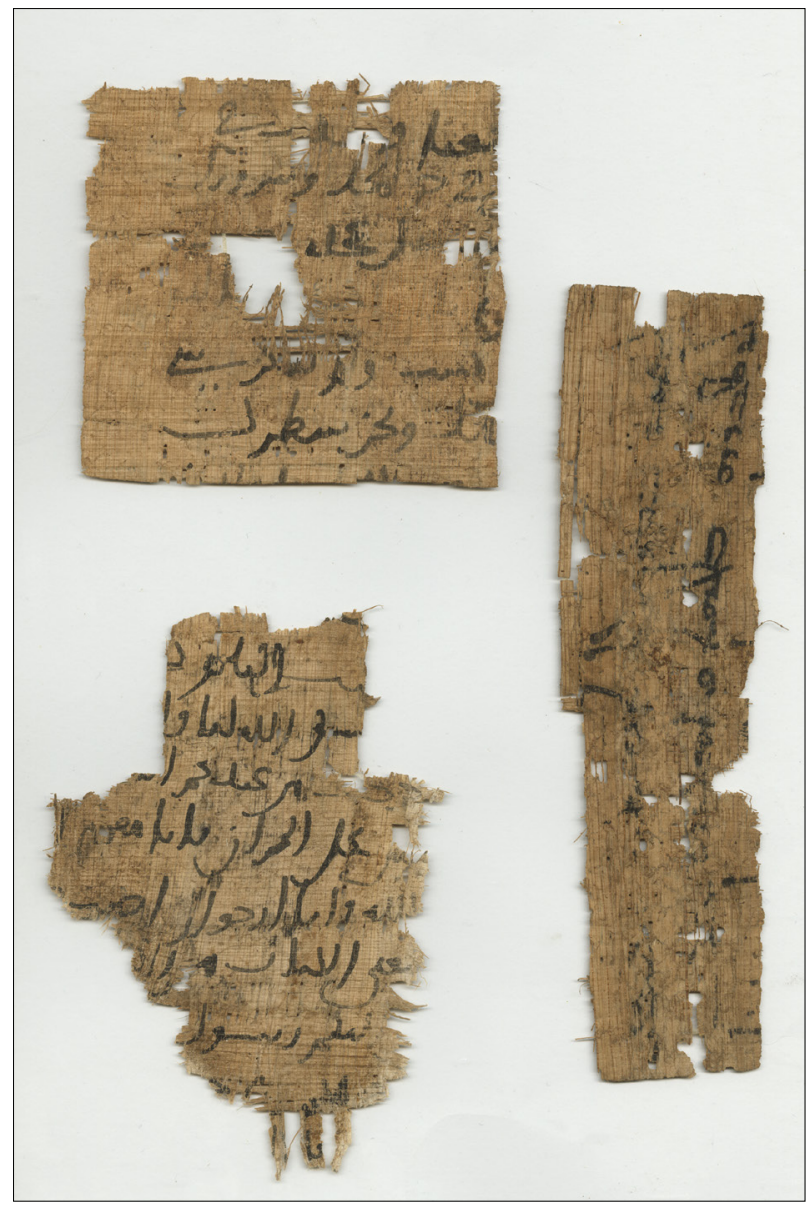

Fig. 7: Undocumented Arabic fragments, CP 184, layer 10. Scan by Museo Egizio.

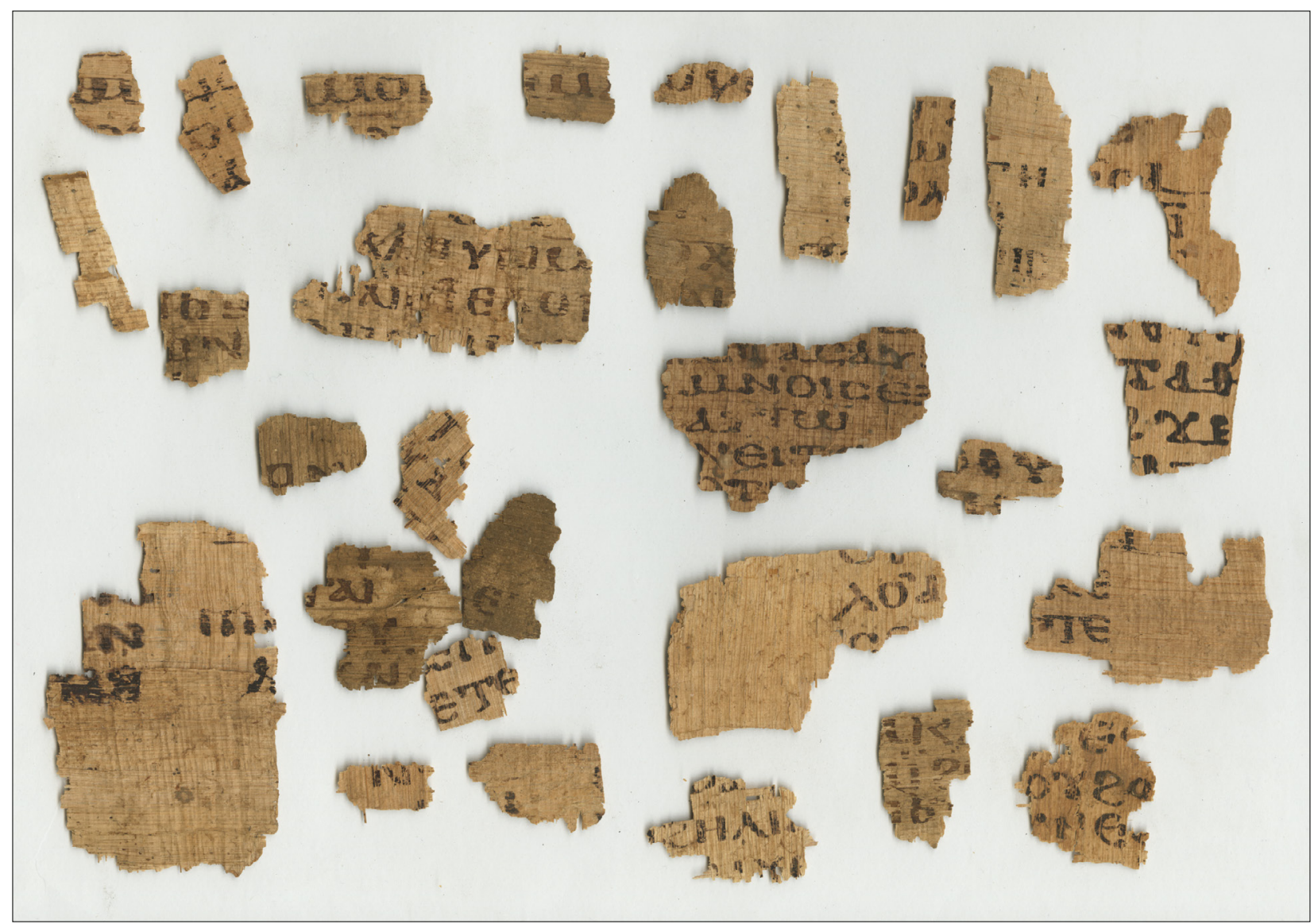

Fig. 8: Undocumented Coptic fragments, CP 183, layer 2. Scan by Museo Egizio. 


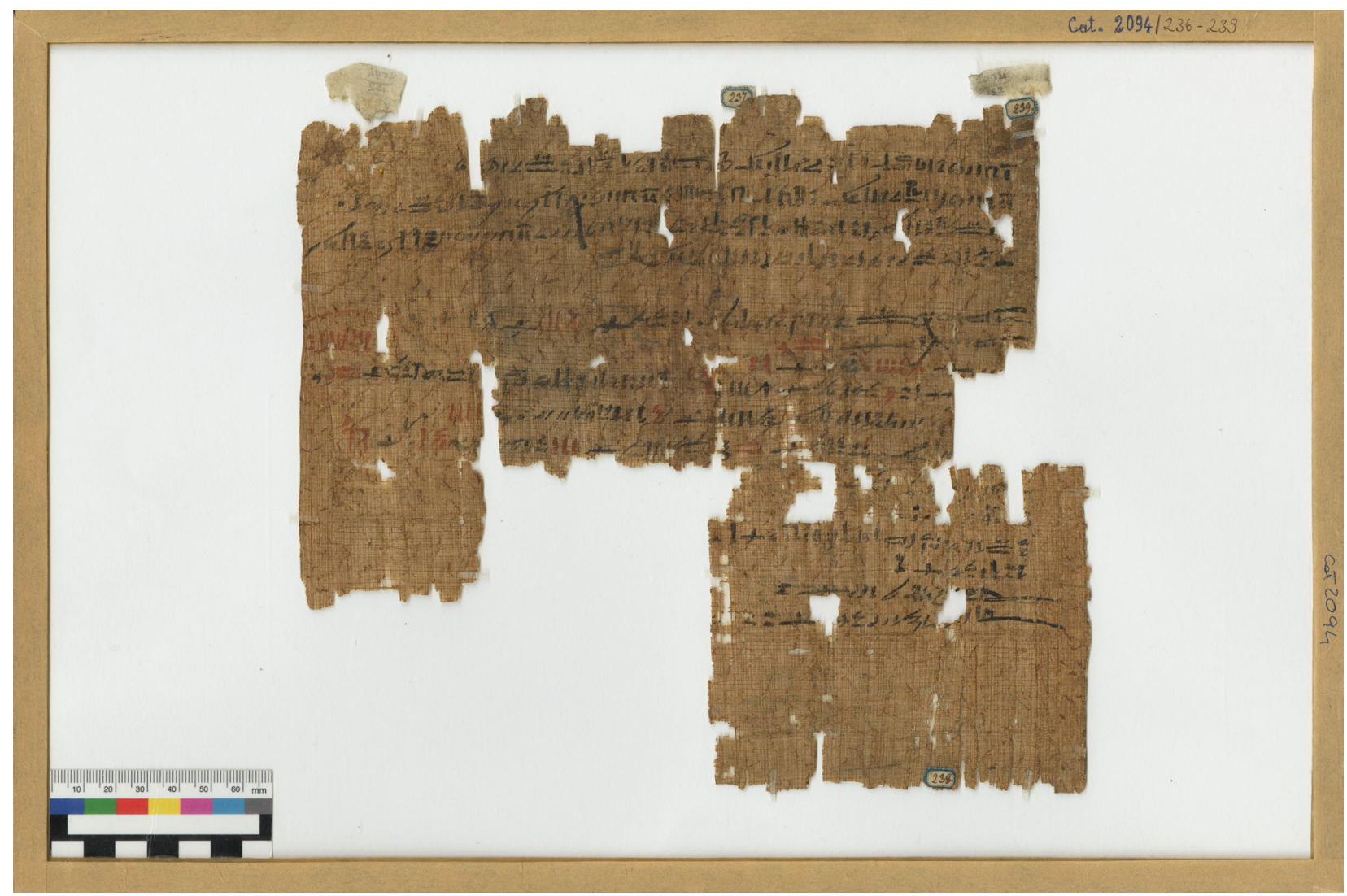

Fig. 9: Document A (recto: journal and account; verso: delivery); P. Turin Cat. 2094/236 + 2094/237 + 2094/238 + 2094/239; Scan by Museo Egizio.

sub-numbers are attached to the fragments, and these labels, when present, are crucial to distinguish the different (fragmentary) manuscripts.

The following example should help to clarify this situation. Cat. 2094 comprises 11 fragments (objects) identified by the sub-numbers $236-246$, which belong to at least four documents (we have not yet managed to identify sub-numbers 240 and 241 in the museum collection):

- Document A (recto: journal and accounts/verso: delivery) Fig. 9 Cat. 2094/236 + Cat. 2094/237 + Cat. 2094/238 + Cat. 2094/239

- Document B (recto: protocol/verso: list) Fig. 10 Cat.2094/242 + Cat.2094/243 + Cat.2094/245 + Cat.2094/246 + Cat.2095/247 + Cat.2095/248 + Cat.2095/250 + Cat.2095/256 + Cat.2068/126 + Cat. 2065/101-105

- Document C (recto/verso: necropolis journal) Cat. 2094/244 + Cat. 1898 + Cat. 1926 + Cat. 1937

The sub-numbers were not always retained in subsequent publications and in online databases (e.g. the Leiden DeM Database and Trismegistos), which

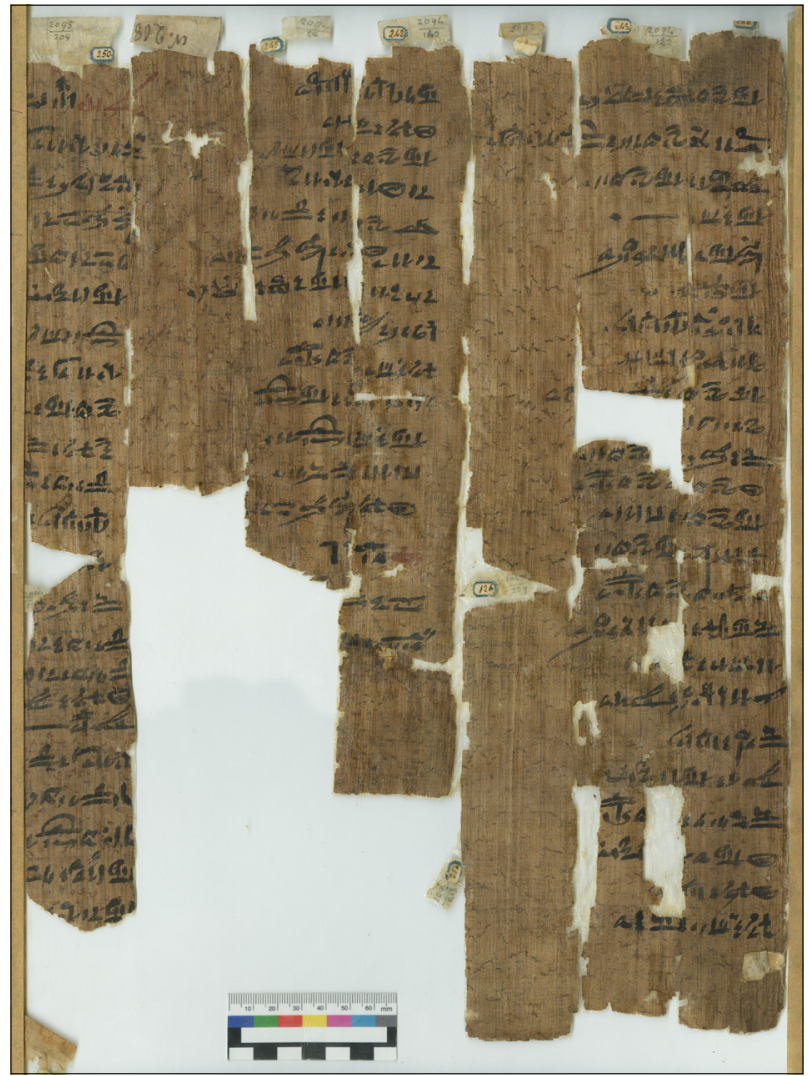

Fig. 10: Document B (recto: protocol / verso: list); P. Turin Cat. 2094/242+2094/243+2094/245+2094/246 $+2095 / 247+2095 / 248+2095 / 250+2095 / 256+$ 2068/126 + 2065/101-105; Scan by Museo Egizio. 
makes the identification of documents based solely on their main inventory number (e.g. Cat. 2094) often difficult. Scholars are encouraged to retain the sub-numbers to allow different documents to be distinguished, and to make sure complete information is provided about the papyri and the texts they bear. I should add that Fabretti et al. were not consistent in their allocation of sub-numbers. In the Cat.
1769-2041 and Cat. 2115-2117 ranges, we quite often find several fragments assembled under one inventory number. These fragments can sometimes be distinguished on the basis of the descriptions and measurements given in the catalogue; in this case, they are numbered consecutively as 001 etc. in the Turin Papyrus Online Platform.

${ }^{17} \mathrm{KRI}$.

${ }^{18}$ Pleyte and Rossi, Papyrus de Turin, 1869-1876.

${ }^{19}$ For a first overview of some of the fragmentary material see Demichelis, Memorie dell'Accademia delle Scienze di Torino 40 (2016), pp. 3-44.

${ }^{20}$ Polis and Razanajao, Bulletin of the Institute of Classical Studies (2016). The TDM is a conceptual data model developed for inscribed material from ancient Egypt that is fully compatible with the standards of the International Council of Museums (ICoM) for the recording of cultural heritage (CIDOC Conceptual Reference Model).

${ }^{21}$ While papyrology - the study of written material from the Hellenistic to the Arab periods - is already in the "digital vanguard" (cf. Reggiani, Digital Papyrology, 2017, pp. 2-10; Berti and Naether, Altertumswissenschaften in a Digital Age, 2016; http:// www.papyri.info), Egyptian philology and most notably the study of hieratic texts has so far been very slow in catching up.

${ }^{22}$ By Serge Rosmorduc. Available at: http://jsesh. qenherkhopeshef.org.

${ }^{23}$ Fabretti et al. Regio Museo di Torino, 1882 and 1888.

${ }^{24}$ Pleyte and Rossi, Papyrus de Turin, 1869-1876.

${ }^{25}$ Including the collaborating partners: Günter Burkard (Munich), Rob J. Demarée (Leiden), Andreas Dorn (Uppsala), Kathrin Gabler (Basel), Maren GoeckeBauer (Munich), Ben J.J. Haring (Leiden), Stéphane Polis (Liège), Lutz Popko (Leipzig) and Daniel Soliman (London).

${ }^{26}$ Martina Landrino started her PhD project “The Archive of Ramesses IX: Administrative Documents Housed in the Museo Egizio" (supervisors H.-W. Fischer-Elfert and B. Haring) in September 2018. The second PhD and the PostDoc will start in 2019.

${ }^{27}$ The "Crossing Boundaries" team is composed of: Antonio Loprieno and Stéphane Polis (Principal Investigators, Basel and Liège, respectively), Kathrin Gabler and Stephan Unter (Basel), Christian Greco and Susanne Töpfer (Turin). A preliminary report on the aims and workflow of the research project will be published by the end of 2019 in the Rivista del Museo Egizio.

${ }^{28}$ For further information on the inventory number system of the Museo Egizio, see the guidelines of the Rivista del Museo Egizio: https://rivista.museoegizio. it/pubblica-con-noi/. 


\section{Bibliography}

Berti, Monica and Franziska Naether, Altertumswissenschaften in a Digital Age: Egyptology, Papyrology and Beyond. Proceedings of a Conference and Workshop in Leipzig, November 4-6, 2015, Leipzig 2016 (online only), http://nbn-resolving.de/ urn:nbn:de:bsz:15-qucosa-201500.

Botti, Giuseppe, L'archivio demotico da Deir el Medineh, Firenze 1967.

Brawanski, Alexander and Hans-Werner Fischer-Elfert, “Der 'erotische' Abschnitt des Turiner Papyrus 55001: Ein Lehrstück für das männliche Ego?”, SAK 41 (2012), pp. 67-97.

Buzi, Paola, Julian Bogdani, Nathan Carlig, Maria Chiara Giorda and Agostino Soldati “'Tracking Papyrus and Parchment Paths': A New International Project on Coptic Literature", Rivista del Museo Egizio 1 (2017), https://doi.org/10.29353/rime.2017.656.

De Buck, Adriaan, “The Judicial Papyrus of Turin”, JEA 23 (1937), pp. 152-64.

Del Vesco, Paolo and Federico Poole, "Deir el-Medina in the Egyptian Museum in Turin: An Overview, and the Way Forward", in Dorn, Andreas and Stéphane Polis (eds.), Outside the Box: Selected Papers from the Conference "Deir el-Medina and the Theban Necropolis in Contact” Liège, 27-29 October 2014, Liège 2018, pp. 97-130.

Demarée, Robert and Dominique Valbelle, Les registres de recensement du village de Deir el-Médineh (le "Stato civile"), Leuven 2011.

Demichelis, Sara, "Ricomporre frammenti. Lavori in corso tra i papiri del Museo Egizio di Torino", Memorie dell'Accademia delle Scienze di Torino, Classe di Scienze Morali, Storiche e Filologiche, Serie V, Vol. 40 (2016), pp. 3-44.

Demichelis, Sara, “I papiri del Museo Egizio”, in Museo Egizio, Modena 2015, pp. 254-65.

Devéria, Théodule, "Le papyrus judiciaire de Turin”, Journas (sér. 6), vol. 8 (1886), pp. 154-95 and vol. 10 (1887), pp. 402-476.

Fabretti, Ariodante, Francesco Rossi and Ridolfo V. Lanzone, Regio Museo di Torino. Antichità egizie (Catalogo generale dei musei di antichità e degli oggetti d'arte raccolti nelle gallerie e biblioteche del regno, 1. Piemonte), Torino 1882 and 1888.

Goyon, Georges, “Le papyrus de Turin dit 'des Mines d'Or' et le Wadi Hammamat”, ASAE 49 (1949), pp. 337-92.

Harrell, James A. and V. Max Brown, "The Oldest Surviving Topographical Map from Ancient Egypt (Turin Papyri 1879, 1899, 1969)", JARCE 29 (1992), pp. 81-105.

$\mathrm{KRI}=$ Kitchen, Kenneth A., Ramesside Inscriptions, Historical and Biographical, 8 vols., Oxford 1975-1990.

Lepsius, Richard, Das Todtenbuch der Ägypter (nach dem hieroglyphischen Papyrus in Turin), Leipzig 1842.

Müller, Matthias, "Der Turiner Streikpapyrus (pTurin 1880)", in Janowski, Bernd and Gernot Wilhelm (eds.), Texte zum Rechts- und Wirtschaftsleben, Gütersloh 2004, pp. 165-84.

Omlin, Joseph A., Der Papyrus 55001 und seine satirischerotischen Zeichnungen und Inschriften, Turin 1973.

Orlandi, Tito, “The Turin Coptic Papyri”, Augustinianum 53 (2013), pp. 501-30.

Peis, Luca, Il papiro di Kha, Monaco 2017.

Pestman, Pieter W., L'archivio di Amenothes, figlio di Horos: Testi demotici e greci relativi ad una famiglia di imbalsamatori del II sec. a.C., Milano 1981.

Pleyte, Willem and Francesco Rossi, Papyrus de Turin: Texte et Planches, Leiden 1869-1876.

Polis, Stéphane and Vincent Razanajao, “Ancient Egyptian Texts in Context: Towards a Conceptual Data Model (the Thot Data Model - TDM)", Bulletin of the Institute of Classical Studies 59/2 (2016), pp. 24-41.

Posener-Kriéger, Paule, I papiri di Gebelein: Scavi G. Farina 1935 (edited by Sara Demichelis), Torino 2004.

Quirke, Stephen, Going Out in Daylight - prt $m$ hrw. The Ancient Egyptian Book of the Dead: Translations, Sources, Meaning, London 2013.

Reggiani, Nicola, Digital Papyrology I: Methods, Tools and Trends, Berlin 2017.

Roccati, Alessandro, Amerigo Bruna and Pieter W. Pestmann, "Supporti scrittori”, in: Anna Maria Donadoni Roveri (ed.), Dal museo al museo: Passato e futuro del Museo Egizio di Torino, Torino 1989, pp. 118-30.

Ryholt, Kim, “The Turin King-List”, Ägypten und Levante 14 (2004), pp. 135-55. 